\title{
Sistem Informasi Administrasi Sekolah Dasar (Studi Kasus : SD Negeri 2 Lingkis)
}

\author{
Greta Guardi Falla ${ }^{1}$, Rusmala Santi ${ }^{2}$, Evi Fadilah ${ }^{3}$ \\ ${ }^{1}$ Sistem Informasi, UIN Raden Fatah Palembang, Palembang, Indonesia \\ 2,3Dosen Sistem Informasi, UIN Raden Fatah Palembang, Palembang, Indonesia \\ Email: 1gretagf1@gmail.com, ${ }^{2}$ rusmalasanti_uin@radendafath.ac.id, \\ 3evifadilah_uin@radenfatah.ac.id
}

\begin{abstract}
Primary schools are educational institutions which are the main source educational data needed by education actors to carry out their duties and profession. All activities of recording or recording data in the school are called with administration, administration in schools there are many kinds and types, one of them student administration. Student administration, there are various kinds of activities carried out, starting from enrollment of new students until students leave the school. And management student administration currently running at SD Negeri 2 Lingkis is currently not very good management, especially in storage so that we need an information system Can support the activities of recording data and reports on school student administration. Purpose This research is to build an Elementary School Student Administration Information System which will be more effective and efficient to support all data recording and reporting activities which will be built with a webbased information system. The method used in the development of the school administration information system is Prototype where this prototype model consists of communication, planning, modeling, construction and delivery. The result of this research SD Negeri 2 Lingkis can make it easier for registranst, student, teacher, administrators and principals in student administration.
\end{abstract}

Keywords: information systems, school administration, student administration, elementary schools, prototype.

\section{PENDAHULUAN}

Sekolah dasar adalah sebuah lembaga pendidikan yang merupakan suatu sumber utama dalam data pendidikan yang diperlukan oleh pelaku pendidikan untuk melaksanakan tugas dan profesinya. Semua kegiatan pencatatan atau perekaman data yang dilakukan di sekolah itu disebut dengan administrasi, administrasi sekolah ada banyak macam dan jenisnya, salah satunya ialah adminisrasi kesiswaan. Administrasi kesiswaan ada berbagai macam kegiatan 


\section{Jurnal Rekayasa Perangkat Lunak Ampera}

Vol. 1, No. 1, February 2020 e-ISSN: 2775-2488

https://journal-computing.org/index.php/journal-sea/index

yang dilakukan, mulai dari pendaftaran siswa baru sampai siswa meninggalkan sekolah tersebut. Dan pengelolaan administrasi kesiswaan yang sedang berjalan di SD Negeri 2 Lingkis sekarang kurang baik dalam pengelolaannya terutama dalam penyimpanan sehingga memerlukan sebuah sistem informasi yang dapat menunjang kegiatan pencatatan data dan laporan pada administrasi kesiswaan sekolah.

Sistem informasi administrasi kesiswaan berbasis web akan dapat mempermudah calon siswa untuk mengetahui informasi tentang SD Negeri 2 Lingkis, memudahkan calon siswa mendaftar online tanpa harus kesekolah, guru tidak harus menemui bagian tata usaha untuk keperluan data siswa, siswa yang ingin pindah sekolah atau disebut mutasi tidak harus bolak-balik kesekolah dalam melakukan pengadministrasian data mutasi yang diperlukan SD Negeri 2 Lingkis dalam pelaporan siswa mutasi, guru dapat langsung melakukan absensi melalui website, menyediakan data pengadministrasian untuk siswa yang lulus melanjutkan sekolah ke SMP/MTs atau yang disebut F1 untuk siswa dan sistem informasi ini dapat mengetahui penyebaran alumni dari SD Negeri 2 Lingkis dengan menyediakan pengelolaan alumni pada sistem informasi administrasi sekolah bagian kesiswaan SD Negeri 2 Lingkis, maka karena itu perlu dibangun suatu sistem informasi yang berjudul "Sistem Informasi Administrasi Sekolah Dasar (Studi Kasus: SD Negeri 2 Lingkis)".

\section{METODE}

Metode penelitian yang digunakan dalam penelitian ini menggunakan pendekatan kualitatif atau dapat disebut dengan penelitian kualitatif. Penelitian metode kualitatif adalah metode penelitian yang berlandaskan pada filsafat postpositivisme, digunakan untuk meneliti pada kondisi obyek yang alamiah, (sebagai lawannnya adalah eksperimen) dimana peneliti sebagai instrumen kunci, teknik pengumpulan data dilakukan secara triangulasi (gabungan), analisis data bersifat induktif/kualitatif, dan hasil penelitian kualitatif lebih menekankan makna dari pada generalisasi. (Sugiyono, 2013:9)

Metode pengembangan sistem yang digunakan yaitu metode Prototype. Metode Prototype merupakan metode pengembangan perangkat lunak yang memungkinkan adanya interaksi antara pengembang sistem dengan pengguna sistem, sehingga dapat mengatasi ketidakserasian antara 


\section{Jurnal Rekayasa Perangkat Lunak Ampera}

Vol. 1, No. 1, February 2020 e-ISSN: 2775-2488

https://journal-computing.org/index.php/journal-sea/index

pengembang dan pengguna (Pressman, 2012:50). Adapun model pengembangan Prototype digambarkan pada Gambar 1:

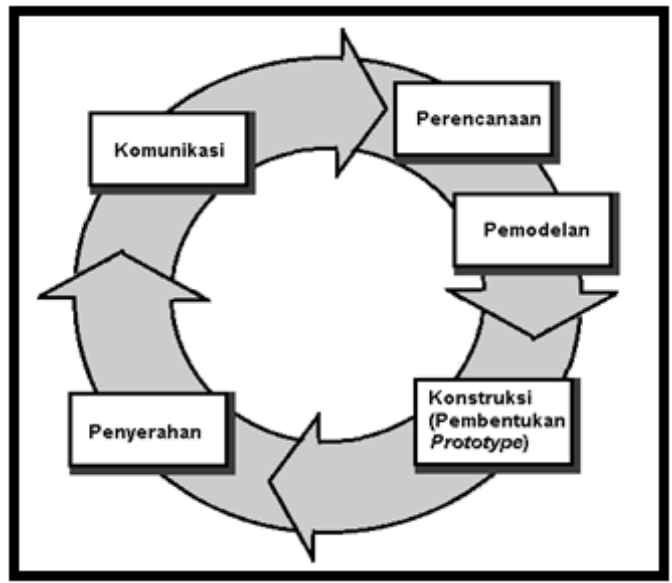

Sumber : Pressman, Roger S., (2012:51)

Gambar 1. Model Prototype

Berikut adalah penjelasan tahapan dalam metode Model prototype:

1) Komunikasi, Komunikasi merupakan tahapan awal dari model prototype guna mengidentifikasi permasalahan-permasalahan yang ada, serta informasi-informasi lain yang diperlukan untuk pengembangan sistem administrasi kesiswaan pada SD Negeri 2 Lingkis.

2) Perencanaan, Perencanaan, tahapan ini dikerjakan dengan kegiatan penentuan sumberdaya, spesifikasi untuk pengembangan berdasarkan kebutuhan sistem, dan tujuan berdasarkan pada hasil komunikasi yang dilakukan agar pengembangan dapat sesuai dengan yang diharapkan.

3) Pemodelan, Pemodelan, tahapan selanjutnya ialah representasi atau menggambarkan model sistem yang akan dikembangkan seperti proses dengan perancangan menggunakan Data Flow Diagram (DFD), relasi antar-entitas yang diperlukan, dan perancangan antarmuka dari sistem yang akan dikembangkan.

4) Konstruksi, Konstruksi, tahapan ini digunakan untuk membangun, menguji-coba sistem yang dikembangkan. Proses instalasi dan penyediaan user-support juga dilakukan agar sistem dapat berjalan dengan sesuai.

5) Penyerahan, Penyerahan, tahapan ini dibutuhkan untuk mendapatkan feedback dari pengguna, sebagai hasil evaluasi dari tahapan sebelumnya dan implementasi dari sistem yang dikembangkan. 


\section{Jurnal Rekayasa Perangkat Lunak Ampera}

Vol. 1, No. 1, February 2020 e-ISSN: 2775-2488

https://journal-computing.org/index.php/journal-sea/index

\section{HASIL DAN PEMBAHASAN}

\subsection{Desain Sistem}

Rancangan sebuah sistem dari hasil analisis sebelumnya yaitu dari data yang ada dan diubah menjadi sebuah web dan sistem basis data MySQL. Berikut tahapan yang diperlukan dalam pembuatan sistem informasi administrasi sekolah dasar:

\section{1) Data Flow Diagram (DFD)}

Menurut Rosa (2016:70), Data Flow Diagram adalah reresentasi grafik yang menggambarkan aliran informasi dan transformasi informasi yang diaplikasikan sebagai data yang mengalir dari masukan (input) dan keluaran (output). Ruang lingkup sistem informasi administrasi kesiswaan seperti diagram kontext pada Gambar 2 berikut ini :

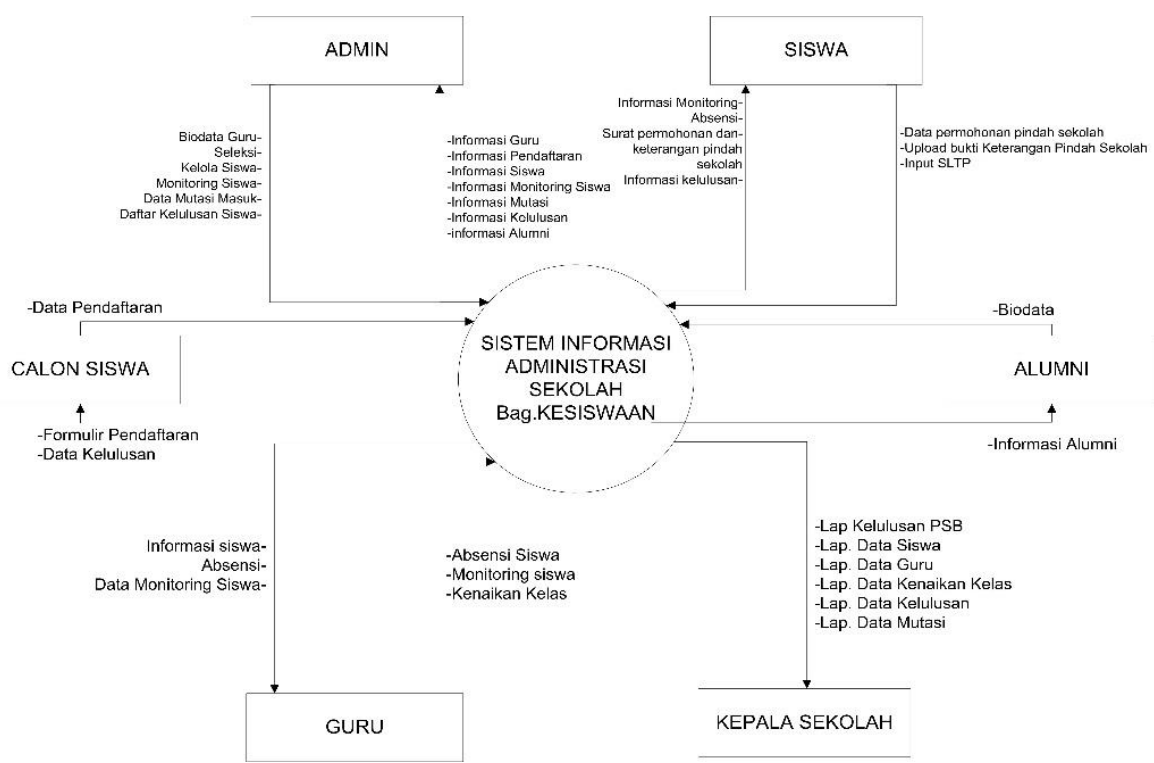

Gambar 2. Diagram Context

Diagram Context dapat diperjelas lebih rinci lagi dengan membuat Data Flow Level 0. Diagram ini merupakan penjelasan lebih lanjut dari proses yang ada pada diagram kontext. Gambaran umum yang ada pada context diagram yaitu : Mengolah pendaftaran, pengelolaan data guru, pengelolaan data siswa, pengelolaan monitoring, pengelolaan absensi, pengelolaan mutasi, dan pengelolaan administrasi ke SLTP. Entitas yang digunakan yaitu admin, calon siswa, siswa, alumni, guru dan kepala sekolah. 


\section{Jurnal Rekayasa Perangkat Lunak Ampera}

Vol. 1, No. 1, February 2020 e-ISSN: 2775-2488

https://journal-computing.org/index.php/journal-sea/index

2) Data Flow Diagram (DFD) Level 0

Diagram nol memberikan pandangan secara menyeluruh mengenai sistem yang ditangani, menunjukkan tentang fungsi atau proses yang ada di sistem, berikut adalah diagram flow diagram level 0.

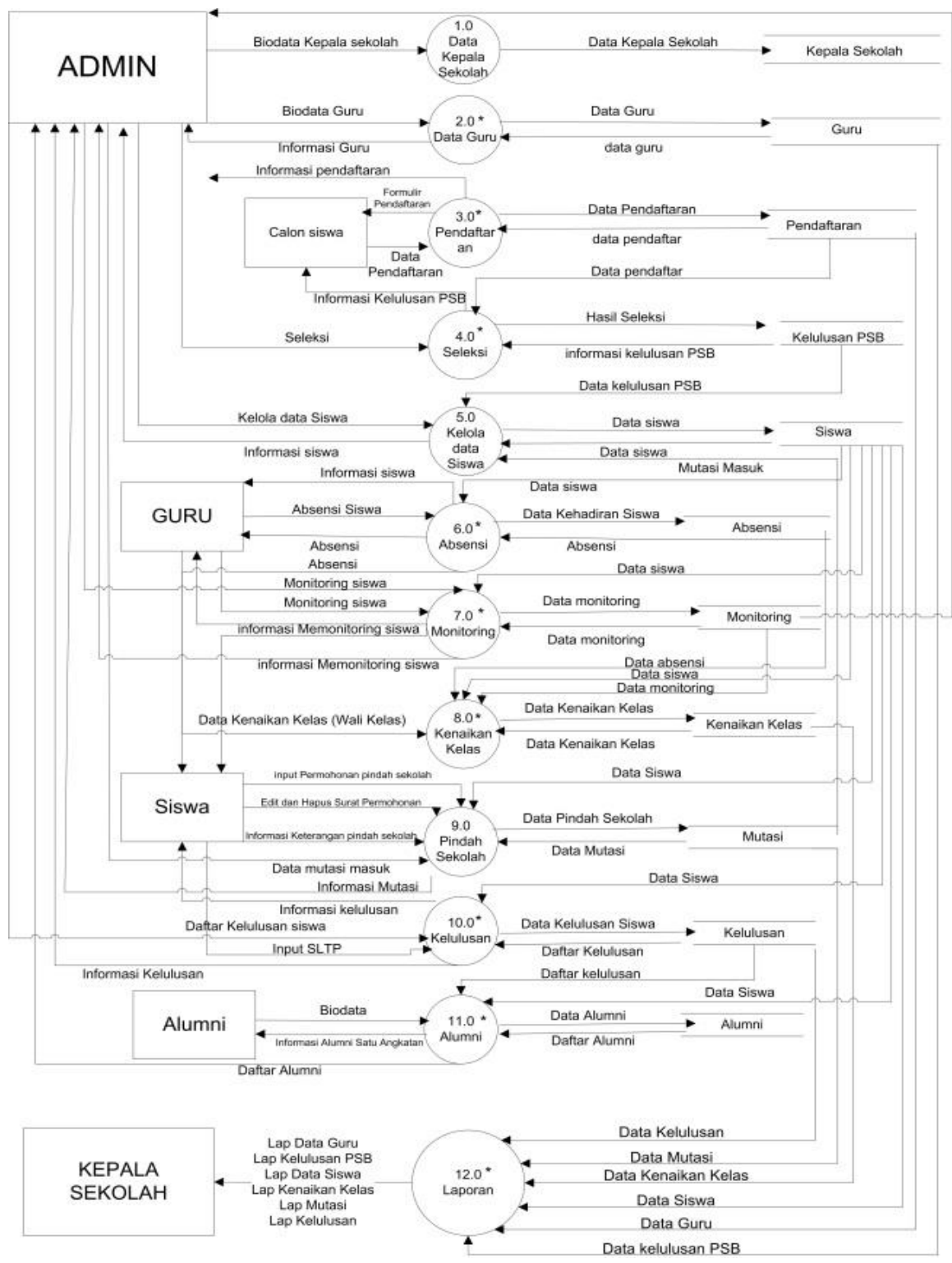

Gambar 3. DFD Level 0 


\section{Jurnal Rekayasa Perangkat Lunak Ampera}

Vol. 1, No. 1, February 2020 e-ISSN: 2775-2488

https://journal-computing.org/index.php/journal-sea/index

\subsection{Hasil Pengembangan}

1) Halaman Home

Halaman home pertama kali ditampilkan pada saat membuka sistem. dimana halaman ini berisikan gambar SD Negeri 2 Lingkis dan memiliki menu pendaftaran dan menu login untuk masuk ke halaman web masing-masing seperti tata usaha, kepala sekolah, guru, siswa, dan calon siswa seperti pada Gambar 4 berikut :

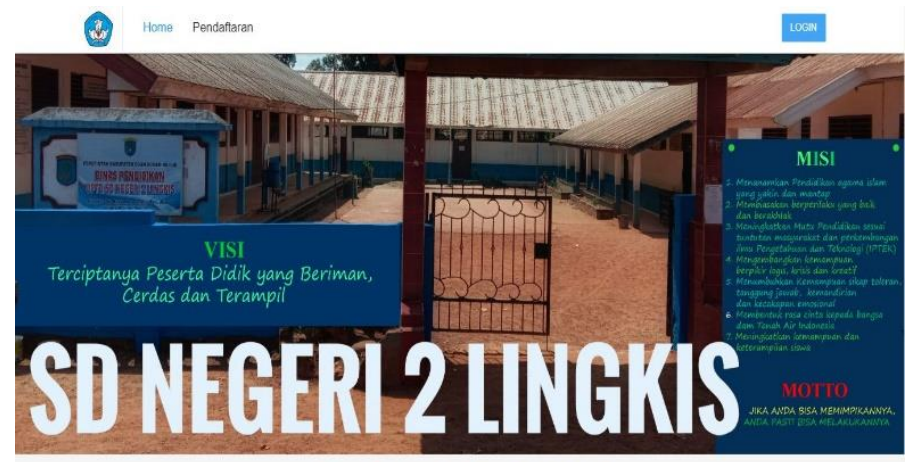

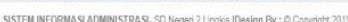

Gambar 4. Halaman Home

\section{2) Halaman Login}

Halaman login berfungsi untuk masuk ke halaman web masing-masing seperti tata usaha, kepala sekolah, guru, siswa, dan calon siswa pada Gambar 5 berikut ini :

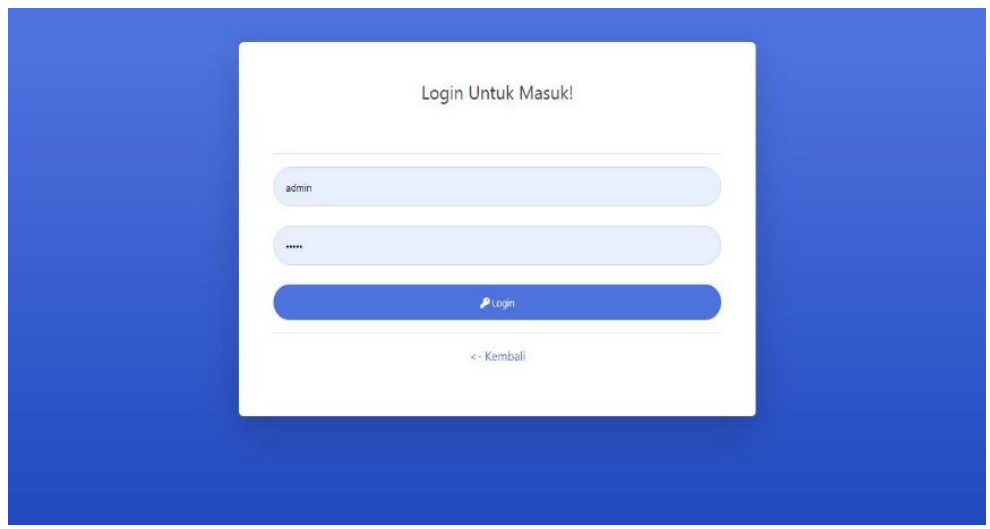

Gambar 5 Halaman Login 


\section{Jurnal Rekayasa Perangkat Lunak Ampera}

Vol. 1, No. 1, February 2020 e-ISSN: 2775-2488

https://journal-computing.org/index.php/journal-sea/index

\section{KESIMPULAN}

Berdasarkan penelitian yang telah dilakukan dengan judul Sistem Informasi Administrasi Sekolah Dasar bagian Kesiswaan, maka dapat disimpulkan yaitu, menghasilkan sistem informasi dibangun dengan menggunakan metode pengembangan Prototype serta menggunakan pemrograman PHP dan MySQL sebagai database yang dapat membantu kegiatan-kegiatan pengolahan penerimaan siswa baru, pengelolaan data siswa, pengelolan administrasi pindah sekolah atau mutasi, pengelolaan absen siswa, pengeolaan sltp siswa dan pengelolaan alumni.

\section{DAFTAR PUSTAKA}

Daryanto, “Administrasi dan Manajemen Sekolah”, 2013.

Enterprise, "Php komplet", 2017.

Fauziah, "Konsep Dasar Perancangan WEB", 2014.

Fran Setiawan, "Intergrasi Basis Data dengan WEB”, 2011.

Gunawan, “Administrasi Sekolah Administrasi Pendidikan Mikro”, 2011.

I Putu Agus Eka Pratama, "Sistem Informasi dan Implementasi" , 2014

Kadir, Abdul, "Pengertian MySql Tersedia dalam : Buku Pintar Programer pemula PHP", 2013.

Kustiyahningsih, Rosa Devie, "Pemprograman Basis Data Berbasis Web Menggunakan PHP dan MySQL", 2011.

Nugroho Bunafit, "Latihan Membuat Aplikasi Web PHP dan MySql dengan Dreamweaver MX(6, 7, 2014) dan 8”, 2009.

Pressman, Roger S, “Rekayasa Perangkat Lunak Pendekatan Praktisi Edisi 7 Terjemahan: Adi Nugroho, George John Leopold Nikijuluw, Theresia Herlina", 2012. 


\section{Jurnal Rekayasa Perangkat Lunak Ampera}

Vol. 1, No. 1, February 2020 e-ISSN: 2775-2488

https://journal-computing.org/index.php/journal-sea/index

Puspitosari, Heni A, "Desain WEB Dinamis dengan PHP dan MySQL Tingkat Dasar Menggunakan Dreamweaver", 2013.

Riyanto, "Kolaborasi MANTAP PHP+jQuery dengan IBM DB2 \& MySQL", 2014.

Rosa, dan Shalahuddin, "Rekayasa Perangkat Lunak Terstruktur dan Berorientasi Objek", 2014.

Rosa, dan Shalahudin. "Rekayasa Perangkat Lunak Terstruktur dan Berorientasi Objek", 2016.

Sibero, Alexander, "Web Programing Power Pack", 2013.

Setiawan, Antonius Fran, "Integrasi Basis Data dengan Web", 2013.

Sitorus, Lamhot, “Algoritma dan Pemrograman”, 2015.

Sugiono, "Metode Penelitian Kualitatif, Kualitatif, dan R\&D", 2011.

Sugiono, "Metode Penelitian Kualitatif, Kualitatif, dan R\&D", 2013.

Sugiono, "Metode Penelitian Kualitatif, Kualitatif, dan R\&D", 2016.

Yunaeti, Irviani, "Pengantar Sistem Informasi", 2017. 